\title{
Flipper-bands on penguins: what is the cost of a life-long commitment?
}

\author{
Boris M. Culik ${ }^{1}$, Rory P. Wilson ${ }^{1}$, Rudolf Bannasch ${ }^{2}$ \\ ${ }^{1}$ Institut für Meereskunde, Düsternbrooker Weg 20, D-24105 Kiel, Germany \\ ${ }^{2}$ FG Bionik, Technische Universität Berlin, Ackerstr. 71-76, D-13355 Berlin, Germany
}

\begin{abstract}
The individual marking of flying and flightless birds has a long history in ornithology. It is the only technique which is cheap, simple and effective, yielding results on bird migration, age-specific annual survival and recruitment. Consequently, hundreds of thousands of birds are annually ringed worldwide. Unfortunately, researchers all too often tend to neglect problems associated with rings and tags. In Antarctic penguins, flipper bands have been used extensively by a variety of nations, and banding is an integral part of the Council for the Conservation of Antarctic Marine Living Resources' (CCAMLR) monitoring programme (Standard method A4). This programme suggests that mortality in penguins wearing bands can be attributed to either (a) prey species availability, (b) predation, (c) weather conditions or (d) other. In this paper, we have attempted to quantify energetic costs associated with wearing a flipper band. For that purpose, freshly caught Adélie penguins $(\mathrm{n}=7)$ were introduced, in Antarctica, into a $21 \mathrm{~m}$ long still-water tunnel, where their behaviour and energy consumption were determined via observation and gas respirometry. Birds were either immediately marked with a flipper band and tested in the tunnel for ca $2 \mathrm{~h}$, and then taken out and tested again after removal of the band, or vice-versa. Flipper bands significantly (ANOVA, $p=0.006$ ) increased the power input of Adélie penguins during swimming by $24 \%$ over the speed range of 1.4 to $2.2 \mathrm{~m} \mathrm{~s}^{-1}$, from $17 \mathrm{~W}$ $\mathrm{kg}^{-1}$ to $21.1 \mathrm{~W} \mathrm{~kg}^{-1}$ ( $\mathrm{n}=115$ and 157 measurements, respectively). The implications of banding on foraging performance and survival of penguins are discussed. Implantable passive transponders could help overcome such problems.
\end{abstract}

\section{INTRODUCTION}

Marking of birds using metal rings around their legs started in 1899, with the Danish researcher H. C. C. Mortensen using this technique for scientific purposes. Individual marking of migratory birds was intended to provide data on migratory speed, direction and behaviour of bird populations, as well as on life expectancy and mortality rates. In addition to the now widely used leg rings, several groups of birds are routinely marked using bill tabs, wing tags, coloured rings and neck bands. The number of birds ringed each year reaches many hundreds of thousands. The marine ornithological station Helgoland (North Sea), for instance, ringed 220000 birds in 1972 and a total of 3.3 million birds from 1909 to 1965 . However, only $25 \%$ of large birds and as few as $1 \%$ of small birds were ever sighted again after marking (Bezzel 1977).
Marking techniques for birds have been reviewed by Marion \& Shamis (1977), Patterson (1978), Spencer (1978) and Day et al. (1980), but these reviews give little information on the adverse effects of banding. At worst, it is possible that data so collected show only the influence of the marking device rather than providing an unbiased picture on some aspect of bird biology. Calvo \& Furness (1992) have compiled information on the effects of marking on birds. For instance on storks Ciconia ciconia, rings may cause leg irritation, injury and even death (Herholdt 1987).

In penguin research, the earlier used tarsus bands (Richdale 1951) were replaced by flipper bands as long ago as 1948 (Sladen 1952). Although Sladen \& Leresche (1970) described flipper bands as being made of aluminium, monel, plastic or teflon, most researchers today use stainless steel (CCAMLR, Standard Method A4, 1992). Although some reservations about the technique have been expressed due to band 
loss (e.g. Weimerskirch et al. 1991), penguin loss due to the band has hardly ever been considered. Sladen \& Penney (1960) and Cooper \& Mordant (1981) report only slight feather wear, whereas Bannasch \& Lundberg (1984) and Sallaberry \& Valencia (1985) found that a large proportion of the Pygoscelid penguins marked with flipper bands on Ardley Island, Antarctica, during 1979 and 1980 (Bannasch \& Odening 1981), had wounds by the breeding season of 1981-82. The bands were consequently removed.

Ainley et al. (1983) first observed that bands 'apparently caused some mortality... Mortality may occur from complications when the wing swells during molt and the band constricts blood flow.' Ainley et al. (1983) assume that a consequent increased mortality of ca $28 \%$ occurs only once: during the first molt, which happens after an Adélie penguin's first year of life, when it is 13 to 14 mo old. The authors were unable to determine whether bands affected survivorship in older birds.

We suggest that an increase in mortality in banded penguins may also be due to other factors. Swimming speed in penguins is affected by drag (Culik \& Wilson 1991a), which is increased by the attachment of devices to the birds (Bannasch et al in press). Since device-equipped penguins do not appear to alter the duration of their foraging trips nor increase their energy expenditure per unit time while at sea, several authors concluded that they swim at reduced speeds (Wilson et al. 1986, Gales et al. 1990, Culik \& Wilson 1992). This ultimately results in a reduced foraging range and, since the probability of prey encounter is dependent on the distance travelled, presumably leads to reduced food intake and thus to reduced overall fitness (Wilson \& Culik 1992).

In this paper, we were, for the first time, able to quantify the effects of flipper bands on swimming speeds and on the energetic costs incurred by penguins while swimming, in Antarctica, in a $21 \mathrm{~m}$ long, still-water swim tunnel.

\section{MATERIAL AND METHODS}

All experiments were carried out on Ardley Island $\left(58^{\circ} 55^{\prime} \mathrm{W}, 62^{\circ} 13^{\prime} \mathrm{S}\right)$. South Shetland Islands, Antarctica, between January 22 and 24, 1992. Seven Adélie penguins Pygoscelis adeliae [mean mass $4070 \pm$ 57 (SE) gl were caught from a nearby beach, weighed, and either immediately placed into a $21 \mathrm{~m}$ long stillwater canal $(n=4)$ or first flipper-banded (using a standard stainless steel band) and then inserted into the canal $(n=3)$. Experiments in the canal lasted 60 to $120 \mathrm{~min}$, ending after the bird had swum continuously for a minimum of $40 \mathrm{~min}$. The bird was then removed from the canal, and, depending on the previous experiment, the band either removed or put on. Following this, the penguin was again placed into the canal for a second series of measurements, after which it was taken back to the capture area and released.

The water canal consisted of a $21 \mathrm{~m}$ long, plywood and steel frame construction, $0.9 \mathrm{~m}$ wide and $0.7 \mathrm{~m}$ deep, sealed with a transparent polyethylene sheet and filled with seawater $\left(4^{\circ} \mathrm{C}\right)$. The canal was covered $10 \mathrm{~cm}$ beneath the water's surface with transparent PVC sheets made conspicuous with netting, to prevent the birds from surfacing while at the same time allowing observation of the bird's behaviour from above. Penguins were only allowed to breathe in 2 wedgeshaped respiration chambers $(\mathrm{vol}=94$ l) placed at each end of the canal. The air in each chamber was circulated with a strong fan (Truma, Munich, Germany) and renewed at a rate of $3000 \mathrm{l} \mathrm{h}^{-1}$ using a seawaterresistant compressor (Vacuubrand, Wertheim, Germany). The air was pumped to a nearby $(25 \mathrm{~m})$ laboratory, where the air flow was determined using a gas and a flow meter (Kobold, Hofheim, Germany) for each of the 2 pumps. A subsample of the air from each chamber was dried (Drierite, Aldrich Chemicals) and passed onto one of 2 paramagnetic gas analysers (Maihak, Hamburg, Germany). Data from each analyser were sampled every $2 \mathrm{~s}$ by a computer. The whole system was calibrated daily and checked for leaks at the beginning and the end of the experiments using known volumes of nitrogen (see Culik \& Wilson 1991b for more details).

The activity and position of the bird were continuously recorded in real time by an observer using a quartz-locked tape recorder (Sony Walkman Professional) and a microphone headset. The observer stood on a ladder placed over the middle of the canal, $3.8 \mathrm{~m}$ above the water surface. Data were later transcribed into computer format, to allow determination of the duration of resting, swimming and other activities as well as computation of swimming speed and distance for each interval. An interval started when the penguin submerged and ended when, after surfacing to breathe in one of the respiration chambers, the bird dived again. All intervals which included activities other than resting and swimming were deleted from the data set.

Oxygen consumption was calculated from nonsteady state conditions using the formula of Woakes \& Butler (1983) as modified by Culik et al. (1990) and Culik \& Wilson (1991b) for periods when the penguin was breathing in one of the chambers (software by Jochim Lage, Kiel, Germany). Activity and respirometry data were then individually matched for each accepted interval, taking into account the lag-time of the respirometry equipment (30 s). Energy consump- 


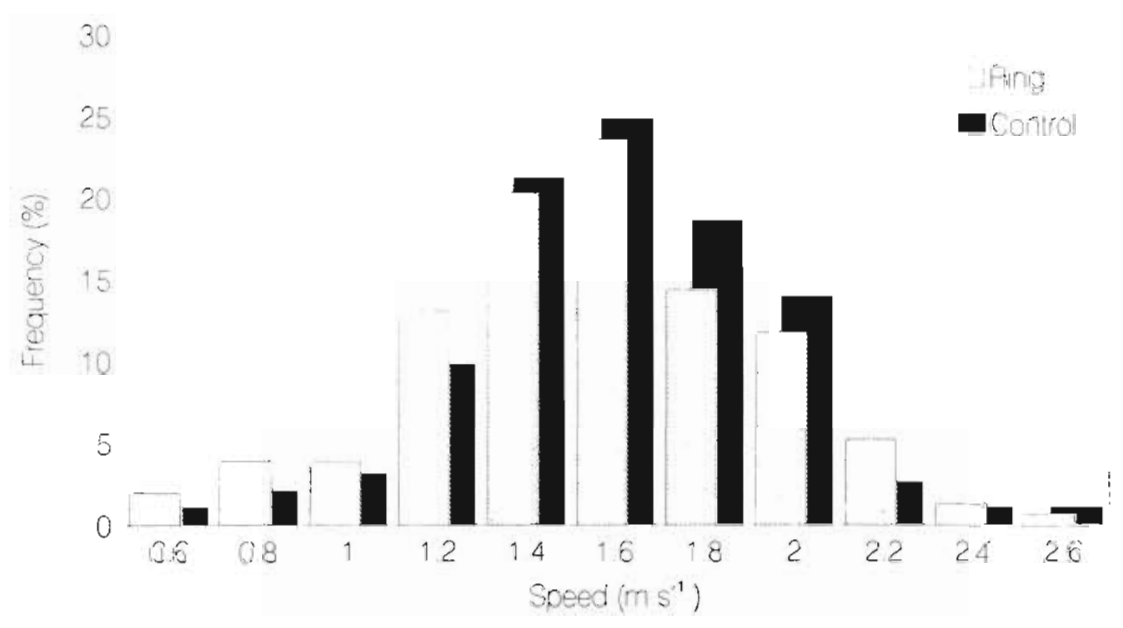

Fig. 1. Pygoscelis adeliae. Comparison of swimming speeds of Adélie penguins $(\mathrm{n}=7)$ in a $21 \mathrm{~m}$ still-water tunnel when ringed using a flipper band ( $n=154$ measurements) and not ringed ( $n=194$ measurements)

tion was calculated from oxygen utilization, using a conversion factor of $20.1 \mathrm{~kJ} \mathrm{l}^{-1} \mathrm{O}_{2}$. Energy consumption (Joules) during swimming $\left(E_{\mathrm{sw}, \mathrm{m}}\right)$ was obtained by

$$
E_{\text {swim }}=E_{\text {Total }}-8.4 \text { Time }_{\text {rest }}
$$

where $E_{\text {Total }}$ is total energy spent for that interval (J); and Time rest is time resting (s) at the surface in one of the chambers (cf. Culik \& Wilson 1991b). Cost of transport was calculated by dividing power $\left(\mathrm{J} \mathrm{kg}^{-1} \mathrm{~s}^{-1}\right)$ by speed $\left(\mathrm{m} \mathrm{s}^{-1}\right)$. All statistical analyses were performed using SYSTAT. Standard errors are given after the \pm sign.

Oxygen consumption in (1) penguins first tested with the flipper band and then without $(n=4)$, or (2) vice versa $(n=3)$, was compared (ANOVA) to determine if the order of the tests was relevant. The difference was not significant at the $p=0.05$ level. This indicates that possible 'noise' due to stress was not altered by wearing a flipper band. Control (without a band) and treatment (with a band) data from all birds were respectively pooled for further analysis.

\section{RESULTS}

Penguins equipped with a flipper band (Fig. 1) swam slightly slower than controls (mean 1.58 vs $1.60 \mathrm{~m} \mathrm{~s}^{-1}$, median 1.575 vs $1.605 \mathrm{~m} \mathrm{~s}^{-1}, \mathrm{n}=154$ vs 194$)$, but the difference was not significant (chi-square test, $\mathrm{p}=0.6$ ).

The mean amount of energy required for swimming at speeds between 1.4 and $2.2 \mathrm{~m} \mathrm{~s}^{-1}$, however, was significantly higher (ANOVA, paired design, $n=7, p=0.006$ ) when the penguins were wearing a flipper band $(21.1 \mathrm{~W}$ $\mathrm{kg}^{-1}, \mathrm{n}=115$ measurements $)$ than without $\left(17.0 \mathrm{~W} \mathrm{~kg}^{-1}\right.$, $\mathrm{n}=157$ measurements). The mean power increase when swimming with a flipper band was $24 \%$.

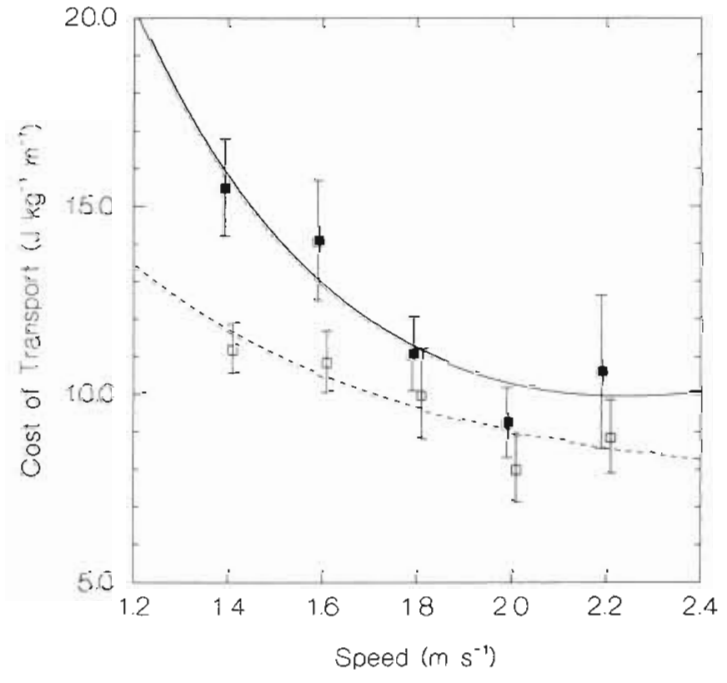

Fig. 2. Pygoscelis adeliae. Cost of transport (COT) in Adélie penguins wearing flipper bands ( $\mathrm{n}=7$, solid line) as opposed to unbanded controls (dotted line). The mean COT is shown for each speed class ( $\pm \mathrm{SE}$ ). COT is lowest near the speed preferred by Adélie penguins in nature $\left(2.2 \mathrm{~m} \mathrm{~s}^{-1}\right)$

A detailed anaysis of the cost of transport $\left(\mathrm{J} \mathrm{kg}^{-1} \mathrm{~m}^{-1}\right)$ for speeds ranging between 1.4 and $2.2 \mathrm{~m} \mathrm{~s}^{-1}$ (Fig. 2) revealed that penguins wearing bands incurred significantly higher costs at all speeds (paired $t$-test, $n=5$, $p=0.009$ ) than controls. In both treatments and controls cost of transport was lowest at 1.8 to $2 \mathrm{~m} \mathrm{~s}^{-1}$.

The power increase (\%) required by the penguins in order to swim with a flipper band (Fig. 3) was calculated from the data presented in Fig. 2. While swimming, cost of transport as well as power $\left(\mathrm{W} \mathrm{kg}^{-1}\right)$ in the banded birds were increased by a maximum of $36 \%$ at $1.4 \mathrm{~m} \mathrm{~s}^{-1}$ ( $\mathrm{n}=31$ treatment vs 41 control), by $28 \%$ at 


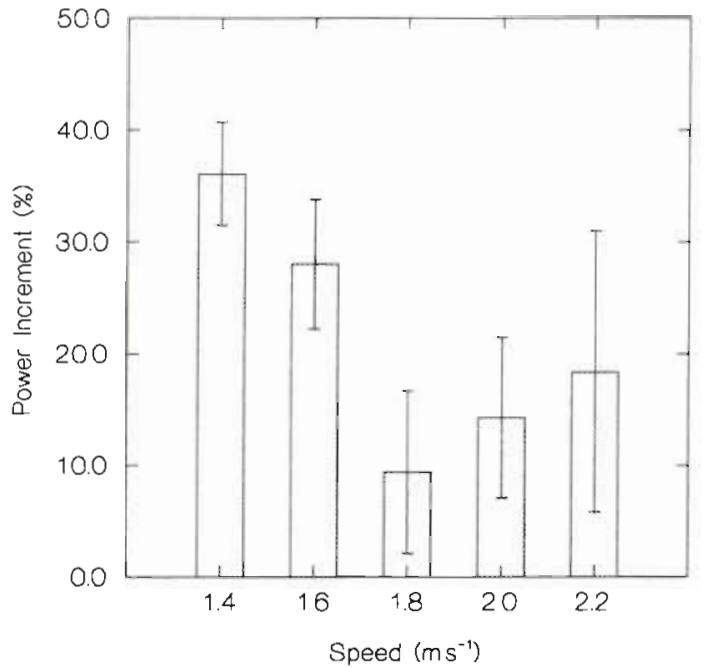

Fig. 3. Pygoscelis adeliae. Mean power increment (\%) required by swimming Adélie penguins to maintain that speed when wearing a flipper band as opposed to controls. Energy expenditure in penguins wearing a band increased by a mean of $24 \%$ over the speed range of 1.4 to $2.2 \mathrm{~m} \mathrm{~s}^{-1}$. Thin bars denote SE

$1.6 \mathrm{~m} \mathrm{~s}^{-1}$ ( $\mathrm{n}=36$ vs 48 ), by a minimum of $9.4 \%$ at $1.8 \mathrm{~m}$ $\mathrm{s}^{-1}(\mathrm{n}=22$ vs 36$)$, by $14.3 \%$ at $2.0 \mathrm{~m} \mathrm{~s}^{-1}(\mathrm{n}=18$ vs 27$)$ and by $18.4 \%$ at $2.2 \mathrm{~m} \mathrm{~s}^{-1}$ ( $\mathrm{n}=8$ vs 5 ) as compared to the unbanded controls.

\section{DISCUSSION}

Flying birds equipped with wing tags have previously been reported to show initial discomfort (Calvo \& Furness 1992). This involves frequent preening, body shaking or pecking at the tag for some time after the attachment (Howe 1980, Stiehl 1983, Maddock 1989). None of these types of behaviours were observed during the short experiments conducted on banded Adélie penguins in the swim canal.

Swimming speeds of banded penguins were not altered compared to speeds chosen when not wearing the band. The mean speeds observed here $\left(1.6 \mathrm{~m} \mathrm{~s}^{-1}\right)$ compare well with swimming speeds of free-living Adélie penguins (2.2 $\mathrm{m} \mathrm{s}^{-1}$; Wilson et al. 1989, 1993). Due to the size limitations of the canal, penguins had to accelerate and decelerate more often (see Culik \& Wilson $1991 \mathrm{~b}$ ) than they would have done in the wild.

In a similar experiment on the effects of instruments on Adélie penguins, Culik \& Wilson (1991a) determined that the birds did not reduce their mean speed in the short term (i.e. in the tunnel) when equipped with an external device. In the long term (i.e. in the wild) it has been suggested that externally instru- mented penguins either reduce speed, foraging range and food uptake as in African penguins Spheniscus demersus and little penguins Eudyptula minor (Wilson et al. 1986, Gales et al. 1990, respectively), or increase foraging trip duration to compensate for device effects as in Adélie penguins (Wilson et al. 1989, Culik \& Wilson 1992). Although very small in comparison to the external device tested by Culik \& Wilson (1991a), the standard flipper bands used in this experiment had the same effect on the birds. In both studies, instrumented or tagged Adélie penguins had to expend $24 \%$ more energy while swimming than untreated.

Unfortunately, it is impossible to compare the effects of flipper bands, as determined here, with studies conducted on penguin models in a water flume (Bannasch et al. in press). Flipper bands are attached loosely to the penguins' propelling organs. The penguin in the wild or in the canal changes the angle of attack, the beat frequency and the loading of its flippers throughout its manoeuvers, and the band plays, due to its loose attachment, varying roles in this. It is however clear that attaching a band onto a highly specialised propelling structure such as a penguins flipper compromises many of its capabilities. The effect is comparable to putting a ring around a blade of a ship's propeller.

Increased energy expenditure during swimming in penguins wearing a flipper band is most likely due to (a) drag and disturbance of wing flow characteristics, (b) physical impairment of the wing, (c) rudder effects of the band or (d) a combination of these. It is conceivable that the data presented here only show short-term effects and that in the long term birds might become accustomed to the band. This is unlikely, however, if drag and disturbed wing flow characteristics are responsible for the increase in energy consumption. These parameters will not improve with time. In the case of (b) and (c), on the other hand, it could be that penguins get used to wearing the band and that their summary efficiency increases with time. We have at present no notion on how long such an acclimation might take. Data in Wilson et al. (1990) on the effects of externally attached devices on penguins suggest that, even after $2 w k$, birds still show the same levels of discomfort as immediately after attachment.

Apart from the studies cited above, there have been a few reports showing that patagial (= wing) tags increase mortality in flying birds. None of the 29 eastern willets Catoptrophorus semipalmatus marked by Howe (1980) returned to the area the following year. He suggests that the wing tags may have increased mortality by increasing drag or by causing abnormal feather replacement during the moult. Flipper bands have been found to cause abrasive feather wear in all penguins at Ardley Island. This has also been reported for other species (Southern 1971, Curtis et al. 1983, 
Kochert et al. 1983). Two long-term studies have shown adverse effects of patagial tags on the reproductive success of ring-billed gulls Larus delawarensis (Southern \& Southern 1985, Kinkel 1989). In both cases, fewer tagged birds returned to the colony site and those returning arrived later than ringed birds. Kinkel considered that the tags may interfere in the migration of the birds, apart from having a pronounced effect on their behaviour and reproduction.

Since Adélie penguins wearing flipper bands must expend $24 \%$ more energy when swimming, we used time-activity budgets to calculate the overall increment in energy expenditure in these birds during the reproductive period. Energy consumption increases by $11 \%$ during incubation, $13 \%$ during brooding and $7 \%$ during the crèche phase (calculated from Culik in press) compared to unbanded conspecifics. This may cause a reduction in breeding success, especially in years with low food availability.

Adélie penguins do not have to provide food for their chicks while incubating, and both parents have access to sufficient food towards the end of incubation. Therefore the amount of fat loss during that period may be considered negligible. We estimate, therefore, that the overall energy increment caused by rings on freeliving Adélie penguins throughout the year is of the order of $11 \%$. This value is directly proportional to the length of the foraging trip.

Considering that (1) about $22.3 \%$ of marked king penguins Aptenodytes patagonicus lost their flipper bands during the first year after banding, and $4.5 \%$ during the second year (Weimerskirch et al. 1991), (2) flipper bands cause irritation, feather wear and wounds (e.g. Sallaberry \& Valencia 1985), (3) penguins with flipper bands have to expend $24 \%$ more energy for swimming and $11 \%$ more energy overall (this study) and (4) flipper bands cause $28 \%$ increased mortality in Adélie penguins during the first year (Ainley et al. 1983), it seems necessary to reconsider the necessity and the usefulness of penguin banding programs, such as the one proposed by CCAMLR.

For ornithologists who still require individual identification of their study bird, there is a way out of this dilemma. Le Maho et al. (1993) have recently published first results of a study conducted since 1991. They report on the use of a new individual identification system (TIRIS, Texas Instruments) which allows animals to be tagged by subcutaneous injection of passive transponders. The transponder tags used are small $(30 \times 3 \mathrm{~mm}$, mass $0.8 \mathrm{~g})$ and do not require batteries. Using a special detector, they allow identification of the bearer from distances of up to $0.7 \mathrm{~m}$.

Although it is too early to assess problems associated with the new method, it offers clear advantages over externally attached markers. Transponder-tagged birds cannot be identified using binoculars as can flipperbanded penguins, but this inconvenience on the part of the researchers is more than balanced by the advantages to the birds and the resulting quality of the data obtained.

Acknowledgements. This study was made possible by a grant from the Deutsche Forschungsgemeinschaft to D. Adelung (A.D 24/11-8). We thank the crew of RV 'Polarstern' and MS 'Columbus Caravelle' for shipping our extensive equipment. We also thank the Alfred Wegener Institute, Bremerhaven, and the personnel of Bellinghausen Station and Base Teniente Marsh for their logistic support. The swim canal was pre-built at our institute in Kiel by G. Dorn, G. Kinzner and U. Lentz.

\section{LITERATURE CITED}

Ainley, D. G., Leresche, R. E., Sladen W. J. L. (1983). Breeding biology of the Adélie penguin. University of California Press, Berkeley

Bannasch, R., Lundberg, U. (1984). Untersuchungen zur Avifauna von King George. Geod. Geoph. Veröff. R. I., H 11 $5-33$

Bannasch, R., Odening, K. (1981). Bei Sturmvogel und Pinguin. Prisma 2: 54-59

Bannasch, R., Wilson, R. P., Culik, B. (in press). Hydrodynamic aspects of design and attachment of a back-mounted device in penguins. $\mathrm{J}$. exp. Biol.

Bezzel, E. (1977). Ornithologie. Ulmer \& Co., Stuttgart,

CCAMLR (Commission for the Conservation of Antarctic Marine Living Resources) (1992). CCAMLR ecosystem monitoring programm, standard methods. CCAMLR, Old Wharf, Hobart, TAS 7000, Australia

Calvo, B., Furness, R. W (1992). A review of the use and the effect of marks and devices on birds. Ringing and Migration 13: 129-151

Cooper, J., Mordant, P. D. (1981). The design of stainless steel flipper bands for penguins. Ostrich 52: 119-123

Culik, B. (in press). Energy expenditure of Adélie penguins In: Dann, P., Normann, I., Reilly, P. (eds.) Advances in penguin biology. Surrey Beatty, Sydney

Culik, B., Wilson, R. P. (1991a). Swimming energetics and performance of instrumented Adélie penguins. J. exp. Biol. 158: $355-368$

Culik, B., Wilson, R. P. (1991b). Energetics of under-water swimming in Adélie penguins. J. comp. Physiol B 161: $285-291$

Culik, B., Wilson R. P. (1992). Field metabolic rates of instrumented penguins using doubly-labelled water. $J$. comp. Physiol. B 162: 567-573

Culik, B., Woakes, A. J., Adelung, D., Wilson, R. P., Coria, N. R., Spairani, H. J. (1990). Energy requirements of Adélie penguin chicks. J. comp. Physiol. B 160: 61-70

Curtis, P. D., Braun, C. E., Ryder, R. A. (1983). Wing markers: visibility, wear and effect on survival of Band-Tailed Pigeons. J. Field Ornithol. 54: 381-386

Day, G. , Schemnitz, S. D., Taber, R. D. (1980). Capturing and marking wild animals. In: Schemnitz, S. D. (ed.). Wildlife management techniques manual. Wildife Society, Washington, DC, p. 61-88

Gales, R., Williams, C., Ritz, D. (1990). Foraging behaviour of the Little penguin: initial results and assessment of instrument effect. J. Zool., Lond. 220:61-85

Herholdt, J. J. (1987). Recovery of a ring-maimed white stork. Safring News 16:82 
Howe, M. (1980). Problems with wing tags: evidence of harm to Willets. J. Field Ornithol. 51: 72-73

Kinkel, L. K. (1989). Lasting effects of wing tabs on Ringbilled gulls. Auk 106: 619-624

Kochert, M. N., Steenhof, K., Moritsch, M. Q. (1983). Evaluation of patagial markers for raptors and ravens. Wildl. Soc. Bull. 11: $271-281$

Le Maho, Y., Gender, J.-P., Challet, E., Bost, C.-A., Gilles, J., Verdon, C., Plumeré, C., Robin, J.-P., Handrich, Y. (1993). Undisturbed breeding penguins as indicators of changes in marine resources. Mar. Ecol. Prog. Ser. 95: 1-6

Maddock, M. (1989). Development and evaluation of a technique for individually marking Egrets. Corella 13: $133-142$

Marion, W. R., Shamis, J. D. (1977). An annotated bibliography of bird marking techniques. Bird Banding 48: $42-61$

Patterson, I. J. (1978). Tags and other distance-recognition markers for birds. In: Stonehouse, B. (ed.) Animal marking. MacMillan Press, London

Richdale, L. E. (1951). Banding and marking penguins. Bird Banding 22: 47

Sallaberry, M., Valencia, D. J. (1985). Wounds due to flipper bands on penquins. J. Field Ornithol. 56: 275-277

Sladen, W. J. L. (1952). Notes on methods of marking penguins. Ibis $94: 541-543$

Sladen, W. J. L., Leresche, R. E. (1970). New and developing techniques in Antarctic ornithology. In: Holdgate M. W. (ed.) Antarctic ecology, Vol. 1. Academic Press, London, p. $585-596$

Sladen, W. J. L., Penney, R. L. (1960). Penguin flipper bands used by the USARP bird banding program 1958-1960. Bird Banding 31: 79-82

This article was submitted to the editor
Southern, W. E. (1971). Evaluation of a plastic wing marker for gull studies. Bird Banding 42: 88-91

Southern, L. K., Southern, W. E. (1985). Some effects of wing tags on breeding Ring-billed gulls. Auk 102: 38-42

Spencer, R. (1978). Ringing and related durable methods of marking birds. In: Stonehouse, B. (ed.) Animal marking. MacMillan Press, London

Stiehl, R. B. (1983). A new attachment for patagial tags. J Field Ornithol. 54: 326-328

Weimerskirch, H., Stahl, J. C., Jouventin, P. (1991). The breeding biology and population dynamics of King Penguins Aptenodytes patagonicus on the Crozet Islands. Ibis 134: $107-117$

Wilson, R. P., Culik, B. (1992). Packages on penguins and device-induced data. In: Priede, I. G., Swift, S. (eds.) Wildlife telemetry. Ellis Horwood, New York, p. $573-580$

Wilson, R. P., Grant, W. S., Duffy, D. C. (1986). Recording devices on free-ranging marine animals: does measurement affect performance? Ecology 67: 1091-1093

Wilson, R. P., Nagy, K. A., Obst, B. S. (1989). Foraging ranges of penguins. Polar Record 25: 303-307

Wilson, R. P., Puetz, K., Bost, C. A., Culik, B. M., Bannasch, R., Reins, T., Adelung, D. (1993). Diel dive depth in penguins in relation to diel vertical migration of prey: whose dinner by candlelight? Mar. Ecol, Prog. Ser. 94: 101-104

Wilson, R. P., Spairanj, H. J., Coria, N. R., Culik, B. M., Adelung, D. (1990). Packages for attachment to seabirds: what colour do Adélie penguins dislike least? J. Wildl. Manage. 54: $447-451$

Woakes, A. J., Butler, P. J. (1983). Swimming and diving in tufted ducks, Aythia fuligula with particular reference to gas exchange. J. exp. Biol. 107: 311-329

Manuscript first received: May 17, 1993

Revised version accepted: June 16, 1993 